УДК 631.358 .42

DOI 10.36910/6775-2313-5352-2021-18-12

Ліннік А.Ю., Фльонц О.В.

Відокремлений підрозділ Національного університету біоресурсів і природокористування України «Бережанський агротехнічний інститут»

\title{
ДОСЛІДЖЕННЯ КІНЕМАТИКО-ДИНАМІЧНИХ ЗВЯЗКІВ ОЧИСНИКА 3 КОРЕНЕПЛОДОМ
}

Зниження собівартості иукрової сировини поряд з підвищенням ї̈ якості дозволить підтримувати та підвищити конкурентноспроможність українських виробників иукру на міжнародному рівні, а також будуть створені передумови для зниження вартості кінцевого продукту на внутрішньому ринку. Одним із шляхів досягнення такої мети виступає застосування таких технічних рішень під час виробництва сировини які забезпечать зниження затрат пращі та енергоємність прочесів виробнищтва.

У статті розглянуто взаємодію очисника з голівкою коренеплоду иукрового буряка з метою дослідження динамічних показників очисника з урахуванням механічних властивостей тіла головки коренеплоду та залишків гички, а також їх геометричних розмірів. Межі допустимого навантаження з боку робочого органу очисника на головку коренеплоду виходячи з умов не пошкодження кореня, але руйнування залишків гички визначено розглянувши контактну задачу взаємодії поверхні очисника-голівка коренеплоду залишок гички. Для аналізу динаміки взаємодії, а саме визначення зусиль, що діють на поверхню коренеплоду та залишки гички, а отже $i$ напружень на поверхні контакту очисника з коренем визначено кінематичні показники кінців лопатей та прутків очисника. Крім того, умови якості виконання процесу очищення голівок коренеплодів будуть залежати від кінематичного режиму роботи очисника, який забезпечить умову відсутності пропусків контакту лопать-поверхня голівки коренеплоду та забезпечить мінімальне пошкодження коренів за рахунок повторного контакту лопатей очисника з коренем. Отримано величину відношення переносної та кутової швидкостей очисника, яка забезпечує відсутність пропусків контакту лопатей очисника з головкою коренеплоду що є коеріиієнтом кінематичного режсиму роботи ротаційного очисника з віссю обертання паралельною до напрямку переносної поступальної швидкості.

Аналіз динамічних та кінематичних параметрів роботи очисника дозволяє вибрати рачіональні параметри роботи машини виходячи з конструктивних особливостей робочих органів, агрофізичних властивостей контактуючих тіл та характеристик агрофону поля.

Ключові слова: гичка, залишки гички, коренеплід, очистка, пляма контакту, модуль пружності, критерій руйнування Треска.

Постановка проблеми. Однією $з$ нагальних проблем при збиранні коренів цукрових та кормових буряків є доочищення голівок коренеплодів. В цій проблемі важливе місце належить розв'язанню задачі якісного доочищення головок коренеплодів від залишків гички при умові збереження цілісності продуктивної частини кореня. Ефективність роботи очисників головок коренеплодів визначають ступінь відокремлення залишків гички та показник пошкодження головок коренеплодів [3]. Це якісні показники, для визначення яких необхідно дослідити динаміку взаємодії робочих органів очисника 3 коренеплодом з урахуванням допустимих напружень у тілі кореня, виходячи 3 критерію його міцності при умові забезпечення максимального відділення залишків гички.

Аналіз останніх досліджень і публікацій При розробці робочих органів та визначенню їх кінематичних та динамічних параметрів часто не зовсім адекватно формулюється задачі. Внаслідок цього до цього часу не існує чіткої теоретично обгрунтованої методики визначення кінематичних та динамічних параметрів та режимів роботи таких робочих органів які б дозволили враховувати механічні властивості та геометричні параметри коренів та залишків гички на них.

Відомі дослідження показників роботи очисників головок коренеплодів показують, що найбільш ефективно працюють очисники ротаційного типу з комбінованими лопатево-пальцевими робочими органами [4]. Теоретичні дослідження стосуються, в основному, взаємодії жорсткого робочого органу з коренеплодом [5], в той час як еластичні робочі органи забезпечують менше пошкодження головок коренеплодів при достатній якості їх очищення від залишків гички. Тому дослідження в цьому напрямку є актуальними та своєчасними. 
Мета досліджень. Метою даної роботи $\epsilon$ визначення динамічних показників роботи доочисника коренеплодів в залежності від механічних властивостей тіла головки коренеплоду та залишків гички а також їх геометричних розмірів.

Результати досліджень. 1. Для визначення меж допустимого навантаження з боку робочого органу очисника на головку коренеплоду з умов не пошкодження кореня але руйнування залишків гички доцільно розглянути контактну задачу поверхня очисника-голівка коренеплоду (залишок гички).

В нашому випадку [6] взаємодію очисника 3 коренеплодом (залишком гички) можна представити схемою що наведена на рис. 1. Тобто у вигляді плоскої задачі контакту двох тіл форми поверхонь обертання.

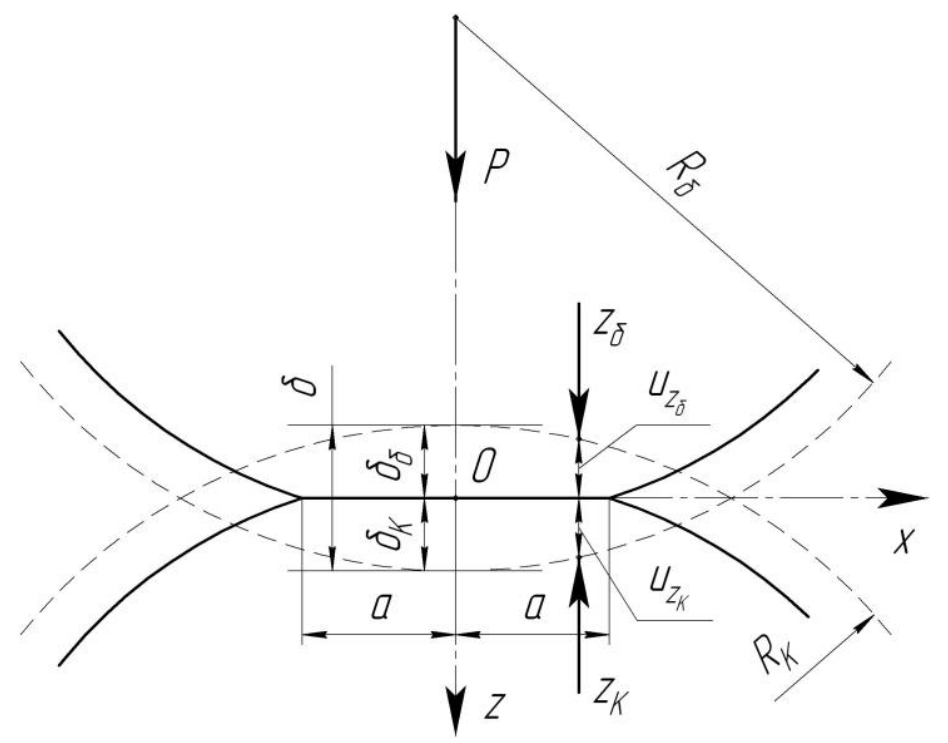

Рис.1. Схема до визначення контакту очисника з голівкою коренеплоду (залишком гички)

В процесі взаємодії два тіла очисник та корінь (в загальному випадку з радіусами кривизни $R_{\hat{a}}$ та $\left.R_{\tilde{a}}\left(R_{\hat{e}}\right)\right)$ контактують по довжині прямолінійної частини довжини $2 a$. При цьому їх центри наближуються на осі на величину $\delta=\delta_{a}+\delta_{\hat{e}}$

Необхідно визначити: розміри плям контакту $2 a$, зближення $u_{z \dot{a}}+u_{z \hat{e}}=\delta=\delta_{\dot{a}}+\delta_{\hat{e}}$; середній нормальний тиск $P_{m}$ і максимальний тиск $P_{o}$.

Якщо точки $S_{\hat{e}}, S_{a}$ поверхонь прийшли у дотик, то

$$
u_{z a}+u_{z \hat{e}}+h=\delta_{\delta}+\delta_{k}=\delta .
$$

Співвідношення між переміщеннями та геометрією контактуючих тіл [1] можуть бути подані у вигляді:

$$
\left(\frac{u_{z \delta}(0)}{a}-\frac{u_{z k}(x)}{a}\right)+\left(\frac{u_{z \delta}(0)}{a}-\frac{u_{z k}(x)}{a}\right)=\frac{1}{2}\left(\frac{1}{R_{\delta}}+\frac{1}{R_{k}}\right) \frac{x^{2}}{a} .
$$

Покладемо, що $x=a$ та введене позначення $u_{z}(0)-u_{z}(a)=d$ тоді (2) прийме вигляд:

$$
\frac{d_{\delta}}{a}+\frac{d_{k}}{a}=\frac{a}{2}\left(\frac{1}{R_{\delta}}+\frac{1}{R_{k}}\right)
$$

Враховуючи, що розмір зони контакту $a=d$ отримуємо, що деформування кожного тіла характеризується відношенням сумарної деформації до напіврозміру зони контакту $d / a$. 3 другого боку величина деформації пропорційна контактному тиску, віднесеному до модуля пружності:

$$
\frac{P_{m}}{E_{\delta}}+\frac{P_{m}}{E_{k}}=a\left(\frac{1}{R_{\delta}}+\frac{1}{R_{k}}\right) \text {, звідки: }
$$

\section{(С Ліннік А.Ю., Фльонц О.В.}




$$
P_{m}=\frac{a\left(\frac{1}{R_{\delta}}+\frac{1}{R_{k}}\right)}{\frac{1}{E_{\delta}}+\frac{1}{E_{k}}},
$$

де $P_{m}$ - середній контактний тиск;

$E_{\delta}, E_{k}$ - модулі пружності тіл, що контактують (бияка та кореня).

Головка кореня буряка має поверхню тіла обертання з конусом $R_{k}$, поверхня очисника має радіус кривизни $R \rightarrow \infty$, тоді відносна кривизна $\frac{1}{R}=\left(\frac{1}{R_{k}}+\frac{1}{\infty}\right)=\frac{1}{R_{k}}$, для простоти будемо писати $\frac{1}{R}$, згідно [1] сумарне переміщення в будь якій точці зони контакту, якщо контакт відбувається по області:

$$
u_{z \hat{a}}+u_{z \hat{e}}=\delta-\frac{r^{2}}{(2 R)},
$$

де $r$ - відстань від центру контакту до місця в якому визначається зближення $\delta$. Розподіл тиску в зоні контакту кругової області [2]:

$$
P=P_{0}\left(1-r^{2} / a^{2}\right)^{\frac{1}{2}}
$$

зумовлює нормальні заміщення:

$$
\begin{gathered}
u_{z}(r)=\frac{1-v^{2}}{\pi E} \frac{P_{0}}{a} \int_{0}^{2 \pi} \frac{\pi}{4}\left(a^{2}-r^{2}+r^{2} \cos ^{2} \varphi\right) R d \varphi= \\
=\frac{1-v^{2}}{E} \frac{\pi P_{0}}{4 a}\left(2 a^{2}-r^{2}\right)
\end{gathered}
$$

де $\varphi$-кут повороту в зоні контакту для полярних координат представлення кругової зони контакту.

Тиск, що діє з боку очисника дорівнює тиску на корінь. Введемо в розгляд приведений модуль пружності $E^{\prime}$ :

$$
\frac{1}{E^{\prime}}=\frac{1-v_{k}^{2}}{E_{k}}+\frac{1-v_{\delta}^{2}}{E_{\delta}}
$$

Перепишемо (4) з урахуванням (6) та (5):

$$
2 \frac{1}{E^{\prime}} \frac{\pi P_{0}}{4 a}\left(2 a^{2}-r^{2}\right)=\delta-\frac{r^{2}}{2 R} .
$$

В центрі зони контакту $u_{z a}+u_{z \hat{e}}=\delta$, а границі зони контакту відповідає значення $r=a$, тому з (7) маємо:

$$
a=\frac{\pi P_{0} R}{4 E^{\prime}}
$$

Зближення тіл (сумарні зміщення) $u_{z \tilde{a}}(0)+u_{z \hat{e}}(0)=\delta$ знаходяться при умові, що $r=0$, тоді з (7):

$$
\delta=\frac{\pi a P_{0}}{2 E^{\prime}}
$$

3 урахуванням властивостей кореня та очисника вирази (8) та (9) перепишуться у вигляд:

$$
a=\frac{\pi P_{0} R_{k}}{2}\left(\frac{1-v_{\delta}^{2}}{E_{\delta}}+\frac{1-v_{k}^{2}}{E_{k}}\right) ; \delta=\frac{\pi a P_{0}}{2}\left(\frac{1-v_{\delta}^{2}}{E_{\delta}}+\frac{1-v_{k}^{2}}{E_{k}}\right) .
$$

Повне навантаження , що стискає очисник та корінь: 


$$
P=\int_{0}^{a} P(r) 2 a r d r=\frac{2}{3} P_{0} \pi a^{2} .
$$

3 виразу (11): $\quad P_{0}=\frac{3 P}{2 \pi a^{2}}$.

Максимальний тиск у зоні контакту від дії повного навантаження в залежності від властивостей кореня та очисника виразиться як:

$$
P_{0}=\frac{\sqrt[3]{6} E_{\delta}^{2 / 3} E_{k}^{2 / 3} P^{1 / 3}}{\pi\left(R^{2}\left(E_{k}\left(v_{\delta}^{2}-1\right)+E_{\delta}\left(v_{k}^{2}-1\right)\right)^{2}\right)^{\frac{1}{3}}} .
$$

[2] :

Максимальні значення напруження будуть знаходитись на осі $o z$, а їх значення згідно

$$
\begin{aligned}
& \sigma_{x}=-\frac{P_{0}}{a}\left[\left(a^{2}+2 z^{2}\right)\left(a^{2}+z^{2}\right)^{-\frac{1}{2}}-2 z\right] ; \\
& \sigma_{z}=-P_{0} a\left(a^{2}+z^{2}\right)^{-\frac{1}{2}} ; \\
& \tau_{x z}=P_{0} a\left[z-z^{2}\left(a^{2}+z^{2}\right)^{-\frac{1}{2}}\right] .
\end{aligned}
$$

Умова руйнування кореня може бути прийнята за Треском у вигляді $\tau_{\max } \leq[\tau]$.

Знайдемо екстремум функції $\tau_{x z}$ з умови $\frac{d \tau_{x z}}{d z}=0$;

звідки $\left.z\right|_{\tau_{x z}=\max }=\sqrt{\frac{1}{2}(\sqrt{5}-1)} \sqrt{a^{2}} \approx 0.78 a$.

При цьому $\tau_{x z \max }=0.3 P_{0} .3$ виразів (12) та (13) можна знайти максимальне значення сили що може діяти на корінь, яка не завдасть йому руйнівних напружень:

$$
P_{\max } \leq \frac{\pi\left(R^{2}\left(E_{k}\left(v_{\delta}^{2}-1\right)+E_{\delta}\left(v_{k}^{2}-1\right)\right)^{2}\right.}{6 E_{\delta}^{2} E_{k}^{2}} \tau_{k}^{3} .
$$

3 другого боку при дії на залишок гички на коренеплоді у виразі (14) сила $P$ повинна перевищувати значення необхідне для руйнування залишка гички:

$$
P_{\min } \geq \frac{\pi\left(R_{2}^{2}\left(E_{\tilde{a}}\left(v_{\delta}^{2}-1\right)+E_{\delta}\left(v_{r}^{2}-1\right)\right)^{2}\right.}{6 E_{\delta}^{2} E_{\tilde{a}}^{2}} \tau_{\tilde{a}}^{3} .
$$

Такими $є$ співвідношення, що визначають значення межі сили, що повинна діяти на коренеплід для забезпечення руйнування залишків гички без пошкодження тіла коренеплоду.

При цьому випадок коли сила $P$ є дотичною до залишку гички може не розглядатися, оскільки в цьому випадку $P_{\min }$ забезпечить злам залишку.

Для аналізу динаміки взаємодії, а саме визначення зусиль, що діють на поверхню коренеплоду та залишки гички, а отже і напружень на поверхні контакту бияків та прутків робочого органа 3 коренем необхідно визначити кінематичні показники кінців лопатей та прутків очисника. Крім того, умови якості виконання процесу очищення голівок коренеплодів будуть залежати від кінематичного режиму роботи очисника, який забезпечить умову відсутності пропусків контакту лопать-поверхня та забезпечить мінімальне пошкодження коренів за рахунок повторного контакту лопатей з коренем.

В загальному випадку, вісь обертання очисника розташована перпендикулярно напрямку руху машини $v_{m}$ (рис.2). При обертанні вала очисника з кутовою швидкістю $w$, кінці лопаті та прутка матимуть колові швидкості у відносному русі [4]:

$$
v_{l o}=w r ; v_{p o}=w R,
$$

де $r, R$ - відповідно довжина лопаті та прутка. 
В абсолютному русі лопаті та прутки робочого органу здійснюють рух по гвинтовій лінії (рис. 3). Параметром цієї гвинтової лінії є величина $S$ (відстань між сусідніми однойменними точками однісї лопаті) за повний оберт робочого органу при проходженні шляху $t_{s} v_{m}$. При цьому час $t_{w}$, за який відбувається повний оберт очисника, дорівнює (за умов наявності однієї лопаті):

$$
t_{w}=\frac{2 \pi}{w} .
$$

А час, за який машина пройде шлях $S$, становить:

$$
t_{s}=\frac{S}{v_{m}}
$$

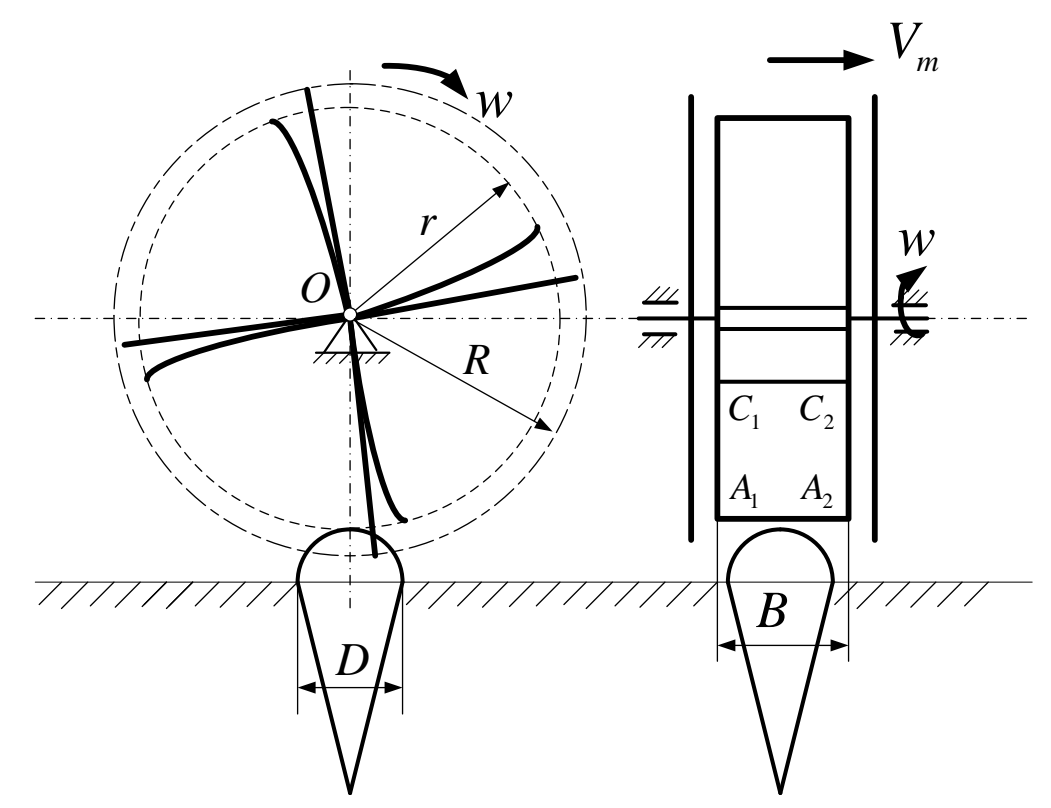

Рис.2. Загальна схема взаємодії очисника з головкою коренеплоду

Для запобігання пропусків контакту лопаті 3 головкою кореня необхідно щоб виконувалась умова: $t_{w} \leq t_{s}$, або $\frac{2 \pi}{w} \leq \frac{S}{v_{m}}$. 3 урахуванням наявності декількох $(n)$ лопатей на роторі, останній вираз матиме вигляд:

$$
\frac{2 \pi}{n w} \leq \frac{S}{v_{m}}
$$

А якщо враховувати ширину лопаті $B$, тобто $S=B$, то останній вираз матиме вигляд: $\frac{2 \pi}{n w} \leq \frac{B}{v_{m}}$. Помноживши праву та ліву частини цього виразу на $v_{m}$ та виконавши деякі перетворення, можна отримати величину відношення переносної та кутової швидкостей очисника, яка забезпечує відсутність пропусків контакту лопатей очисника 3 головкою коренеплоду:

$$
\frac{v_{m}}{w} \leq \frac{B n}{2 \pi} .
$$

Таким чином вираз (20) є коефіцієнтом кінематичного режиму роботи ротаційного очисника 3 віссю обертання паралельною до напрямку переносної поступальної швидкості (швидкості машини). 


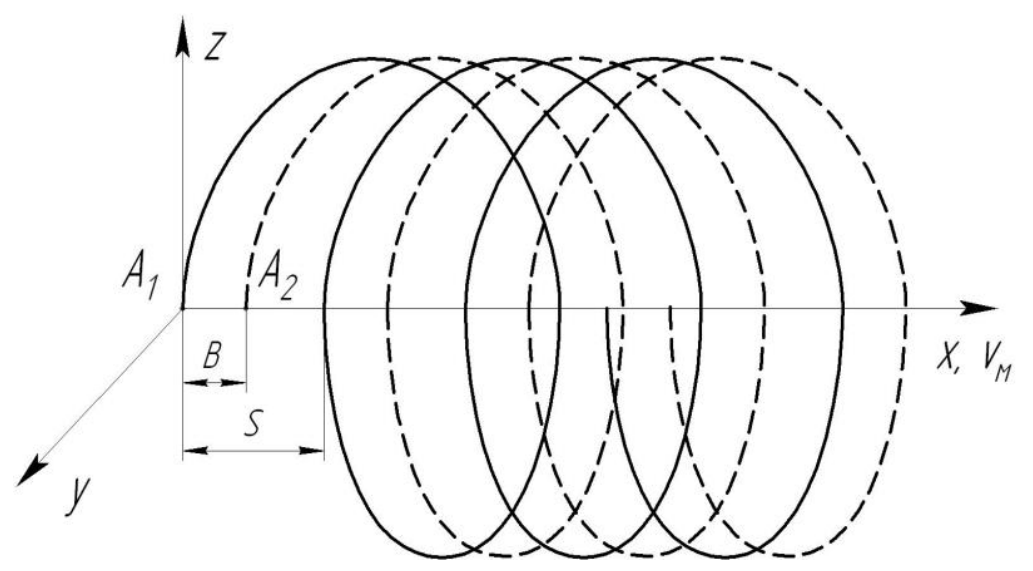

Рис. 3. Траєкторія абсолютного руху кінцевих точок лопаті та прутка очисника коренеплодів

Абсолютні швидкості кінця лопаті та пальця становлять:

$$
v_{l}=\sqrt{v_{m}^{2}+r^{2} w^{2}} ; v_{p}=\sqrt{v_{m}^{2}+R^{2} w^{2}} .
$$

Величина $v_{m}$ визначається технологічними можливостями агрегату, а величина $w$ та конструктивні параметри очисника можуть бути обгрунтовані на основі динамічного аналізу взаємодії лопать - голівка коренеплоду з урахуванням допустимих динамічних навантажень, тобто руйнування гички і відсутності пошкоджень тіла коренеплоду. Виразивши з (2) $w$ та підставивши в останні вирази, можна отримати:

$$
v_{l}=v_{m} \sqrt{1+r^{2}\left(\frac{2 \pi}{n B}\right)^{2}} ; v_{p}=v_{m} \sqrt{1+R^{2}\left(\frac{2 \pi}{n B}\right)^{2}}
$$

Слід відзначити, що за умов рівномірного переносного руху, тобто постійної швидкості переміщення, прискорення кінця лопаті та кінця пальця при гвинтовому русі залежать лише від їх радіусів та кутової швидкості:

$$
a_{l}=r w^{2} ; a_{p}=R w^{2} .
$$

Враховуючи прискорення лопаті в точці контакту зусилля, що діє з боку очисника на головку коренеплоду визначиться як:

$$
F=M_{l} r w^{2},
$$

де $M_{l}$ - маса очисника, приведена до точки контакту.

Приведена маса $M_{l}$ може бути визначена враховуючи умову, що кінетична енергія всієї системи відносно точки обертання дорівнює кінетичній енергії відносно точки контакту.

Кінетична енергія всієї системи при складному русі становить:

$$
T_{s}=\frac{1}{2} I_{o} w^{2}+\frac{1}{2} m_{s} v_{m}^{2},
$$

де $I_{o}$ - момент інерції всієї системи відносно точки обертання;

$m_{s}$ - маса робочого органа очисника.

Момент інерції системи виражається наступним чином:

$$
I_{o}=I_{o l}+I_{o p}+I_{o m} .
$$

Складова, що описує момент інерції лопатей $I_{o l}$ визначається за виразом:

$$
I_{o l}=n \int r^{2} d m, d m=\rho_{l} d V,
$$

де $\rho_{l}$ - густина матеріалу лопаті.

Враховуючи те, що лопать має прямокутний перетин та постійну густину матеріалу $\rho_{l}$, момент інерції лопатей матиме вигляд:

$$
I_{o l}=n\left(r^{3} / 3\right) B \delta_{l} \rho_{l},
$$

\section{(С Ліннік А.Ю., Фльонц О.В.}


де $\delta_{l}$ - товщина лопаті.

Складова, що описує момент інерції прутків $I_{o p}$ визначається наступним чином:

$$
I_{o p}=2 n \int R^{2} d m, d m=\rho_{p} d V,
$$

де $\rho_{p}$ - густина матеріалу прутка.

Складова моменту інерції, що характеризує прутки постійного круглого перетину $d$, кількість яких вдвічі більша за кількість лопатей матиме вигляд:

$$
I_{o p}=2 n\left(R^{3} / 3\right)\left(\pi d^{2} / 4\right) \rho_{p} .
$$

Складова моменту інерції маточини $I_{\text {om }}$ та частин опор робочого органу, що обертаються, мають незначну величину у порівнянні з моментами інерції лопатей та прутків через малий радіус, крім того, оскільки суттєво змінити його конструктивні параметри не можливо, то ним можна знехтувати, або прийняти за постійну величину.

Кінетична енергія всієї системи при складному русі робочого органу в розгорнутому вигляді становить:

$$
T_{s}=\frac{1}{2}\left(m_{p o}+m_{m}\right) v_{m}{ }^{2}+\frac{1}{2} I_{o m} w^{2}+\frac{1}{2} w^{2}\left(2 n \frac{R^{3}}{3} \rho_{p} \frac{\pi d^{2}}{4}+n \frac{r^{3}}{3} \rho_{l} \delta_{l} B\right),
$$

де $m_{p o}=2 n R \rho_{p} \frac{\pi d^{2}}{4}+n \frac{r}{3} \rho_{l} \delta_{l} B$ - маса робочого органа без врахування маси маточини та підшипникових вузлів.

Кінетична енергія системи, приведена до точки контакту лопаті 3 головкою коренеплоду, становить:

$$
T_{k}=\frac{1}{2} v_{l}^{2} M_{l},
$$

де $M_{l}$ - маса системи, приведена до точки контакту.

Підставивши в вираз (31) значення $w$ та $v_{m} 3$ (20), (22) та прирівнявши вирази (31) та (32), можна отримати приведену до точки контакту масу системи:

$$
M_{l}=\frac{12 \pi^{2} I_{o m}+n\left(3 B^{2} n m_{m}+3 B^{2} n m_{p o}+4 \pi^{2} r^{3} \delta_{l} \rho_{l}+2 d^{2} \pi^{3} R^{3} \rho_{p}\right)}{3\left(B^{2} n^{2}+4 \pi^{2} r^{2}\right)} .
$$

За умов абсолютно жорсткої лопаті сила удару по головці коренеплоду визначиться виразом (24) з урахуванням (33).

У випадку, коли лопать деформується при ударі по головці коренеплоду частина кінетичної енергії лопаті буде витрачатися на деформування самої лопаті (прогин). При цьому, потенціальна енергія прогину становить:

$$
U=\frac{1}{2} \int_{r_{0}}^{r} \frac{M^{2}(z)}{E I} d z
$$

де $I=\frac{B \delta^{3}}{12}$ - момент інерції поперечного перетину лопаті;

$r_{0}, r$ - радіус початку та кінця лопаті;

$E$ - модуль пружності матеріалу лопаті.

Кінетична енергія удару лопаті по головці коренеплоду становитиме різницю між повною кінетичною енергією та потенціальною енергією згину лопаті:

$$
T=\frac{1}{2} v_{l}^{2} M_{l}-\frac{6 F^{2}\left(r-r_{0}\right)^{3}}{B E \delta^{3}} .
$$

В кінцевому вигляді кінетична енергія удару лопаті по коренеплоду з урахуванням втрати енергії на деформацію самої лопаті матиме вигляд: 


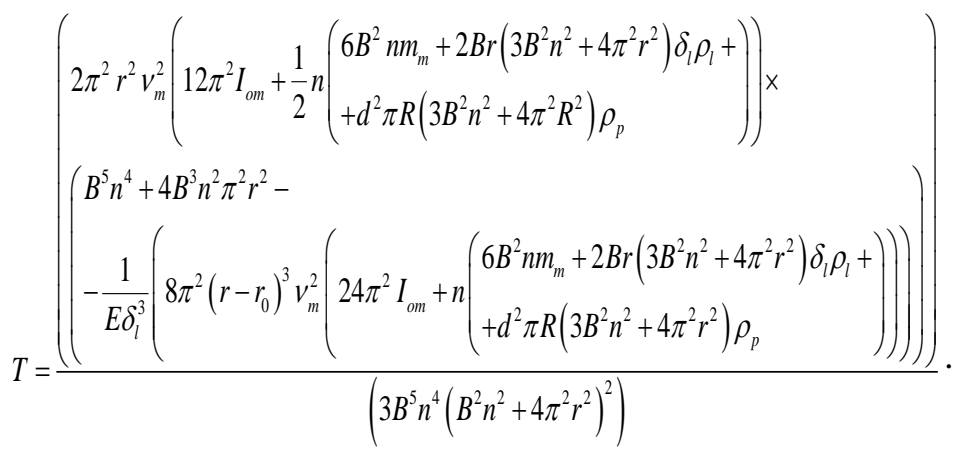

Залежність (36) дозволяє визначити динамічні навантаження на головку коренеплоду в залежності від конструктивних та кінематичних параметрів очисника та матеріалів, що можуть застосовуватись для виготовлення його лопатей та пальців.

Висновки. На основі проведеного аналізу встановлені граничні значення сили, що може діяти на головку коренеплоду в залежності від його геометричних розмірів та розмірів залишку гички, а також їх механічних властивостей (модулів пружності та коефіцієнтів Пуассона) для забезпечення руйнування залишків гички без пошкодження тіла коренеплоду. Для забезпечення виконання умов руйнування залишків гички без пошкодження головки коренеплоду визначені залежності динамічної дії бияка робочого органу в залежності від конструктивних параметрів та кінематичного режиму роботи доочисника.

\section{Інформаційні джерела}

1. Джонсон К. Механика контактного взаимодействия. - М.: Мир, 1989. -510 с.

2. Галин Л.А. Контактные задачи теории упругости и вязкоупругости. - М.: Наука, 1980. $304 \mathrm{c}$.

3. Свеклоуборочные машины: история, конструкция, теория, прогноз. Л.В. Погорелый, Н.В. Татьянко. - К.: Феникс, 2004.-232с.

4. Хелемендик М.М. Напрями і методи розробки робочих органів сільськогосподарських машин.-К.: Аграрна наука, 2001. - 280с.

5. Ліннік А. Визначення динамічних параметрів жорсткого очисника при взасмодії 3 коренеплодом Вісник Тернопільського національного технічного університету - 2014. №1(73) C. $165-171$

6. Ліннік А. Обгрунтування конструкції апарату для очищення голівок коренеплодів цукрових буряків. Вісник аграрної науки Причорномор'я - Миколаїв: МНАУ. -2014 - № 2 (78). C.200-205

Линник А.Ю., Фльонц О.В.

Отделенное подразделение Национального университета биоресурсов и природопользование Украины "Бережанський агротехнический институт"

\section{ИССЛЕДОВАНИЕ КИНЕМАТИКО-ДИНАМИЧЕСКИХ СВЯЗЕЙ ОЧИСТИТЕЛЯ С КОРНЕПЛОДОМ}

Снижение себестоимости сахарного сырья наряду с повышением его качества позволит поддерживать и повысить конкурентоспособность украинских производителей сахара на международном уровне, а также будут созданы предпосылки для снижения стоимости конечного продукта на внутреннем рынке. Одним из путей достижения этой цели выступает применение таких технических решений при производстве сырья которые обеспечат снижение затрат труда и энергоемкость прочессов производства.

В статье рассмотрено взаимодействие очистителя с головкой корнеплода сахарной свекль с иелью исследования динамических показателей очистителя с учетом механических свойств тела головки корнеплода и остатков ботвы, а также их геометрических размеров. Предель допустимой нагрузки со стороны рабочего органа очистителя на головку корнеплода исходя из условий не повреждения корня, но разрушение остатков ботвы определенно рассмотрев контактную задачу взаимодействия поверхности очисника-головка корнеплода остаток ботвы. Для анализа динамики взаимодействия, а именно определение усилий, которые действуют на поверхность корнеплода и остатки ботвы, а следовательно и напряжений на поверхности контакта очистителя с корнем определены кинематические показатели концов

\section{(С Ліннік А.Ю., Фльонц О.В.}


лопастей и прутков очистителя. Кроме того, условия качества выполнения прочесса очистки головок корнеплодов будут зависеть от кинематического режима работь очистителя, который обеспечит условие отсутствия пропусков контакта лопасть-поверхность головки корнеплода и обеспечит минимальное повреждение корешей за счет повторного контакта лопастей очистителя с корнем. Получена величина отношения переносной и угловой скоростей очистителя, которая обеспечивает отсутствие пропусков контакта лопастей очистителя с головкой корнеплода что является коэффициентом кинематического режима работь ротационного очистителя $c$ осью вращения параллельной $\kappa$ направлению переносной поступательной скорости.

Анализ динамических и кинематических параметров работы очистителя позволяет выбрать рачиональные параметры работы машины исходя из конструктивных особенностей рабочих органов, агрофизических свойств контактирующих тел и характеристик агрофона.

Ключевые слова: ботва, остатки ботвы, корнеплод, очистка, пятно контакта, модуль упругости, критерий разрушения Треска.

\section{Linnik A., Flonts $\mathbf{O}$.}

Separated Subdivision of National University of Life and Environmental Sciences of Ukraine Berezhany Agrotechnical institute

\section{INVESTIGATION OF THE KINEMATIC AND DYNAMIC RELATIONSHIPS OF THE CLEANER WITH THE ROOT CROP}

Reducing the cost of sugar raw materials along with improving its quality will help maintain and increase the competitiveness of Ukrainian sugar producers at the international level, as well as create prerequisites for reducing the cost of the final product in the domestic market. One of the ways to achieve this goal is the use of such technical solutions in the production of raw materials that will reduce labor costs and energy consumption of production processes.

In the article, co-operating of purifier is considered with the head of root crop of sugar beet with the purpose of research of dynamic indexes of purifier taking into account mechanical properties of body of head of root crop and bits and pieces of tops, and also their geometrical sizes. Limits of the possible loading from the side of working organ of purifier on the head of root crop coming from terms not damages of root, but destruction of bits and pieces of tops certainly considering pin task of co-operation of surface очисника-головка of root crop remain of tops. For the analysis of dynamics of co-operation, namely determination of efforts that operate on the surface of root crop and bits and pieces of tops, and consequently and tensions on the surface of contact of purifier with a root the kinematics indexes of ends of blades and прутков are certain. In addition, quality of implementation of process of cleaning of root crops will depend on the kinematics mode of operations of purifier that will provide the condition of absence of admissions of contact surface of head of root crop and will provide the minimum damage of chums due to the repeated contact of blades of purifier with a root. The size of relation is got portable and angular speeds of purifier, that provides absence of admissions of contact of blades of purifier with the head of root crop that is the coefficient of the kinematics mode of operations of rotary purifier with the axis of rotation parallel to direction portable forward

The analysis of dynamic and kinematics parameters of work of purifier allows to choose the rational parameters of work of machine coming from the structural features of working organs, agrophysics properties of contacting bodies and field descriptions.

Keywords: tops, bits and pieces of tops, root crop, cleaning, spot of contact, module of resiliency, a criterion of destruction is Tresk. 